\title{
Positive Control
}

National Cancer Institute

\section{Source}

National Cancer Institute. Positive Control. NCI Thesaurus. Code C64356.

A control sample that is known to produce a positive result if the test is working as expected. 